\title{
La recuperación de la hegemonía norteamericana
}

La discusión acerca del retorno de la hegemonía es mucho más compleja de lo que los indicadores económicos más evidentes son capaces de demostrar. Para evitar malos entendidos, conviene advertir desde ahora que nuestra hipótesis del retorno de la hegemonía norteamericana no se basa en la presunción de que el comportamiento del valor del dólar y de la tasa de crecimiento interno se habrán de mantener.

El núcieo del problema ni siquiera reside en el mayor poder económico y militar de potencia dominante, sino en su capacidad de encuadrar a sus socios y adversarios en el plano económico-financiero y político-ideológico. Este poder se debe menos a la presencia transnacional de sus bancos y corporaciones en sus áreas de operación que a una visión estratégica de la élite financiera y militar norteamericana, que se reforzó con la victoria de Reagan. En verdad, sus socios o rivales capitalistas son compelidos, no sólo a someterse, sino a racionalizar la visión dominante como la "única posible". Esta racionalización en materia de política económica se produce por la aceptación de la necesidad de un ajuste recesivo que corresponde a una sincronización de la política económica y de la ideología conservadora a escala mundial, sin precedentes. En términos estratégicos y militares, pasa por una visión de la "guerra" en que se reconoce que los intereses generales de la seguridad mundial están sustancialmente bien defendidos por la gran potencia americana. Vale decir, significa la aceptación por parte de la élite política mundial de que el Presidente Reagan no es un "loco" sino un "hombre resuelto que se impone a sus adversarios" y que está dando la "línea justa" para el resto del mundo capitalista.

Lo que este ensayo pretende demostrar es cómo esta victoria "política-ideológica" estuvo precedida de un reencuadramiento, por parte del gobierno norteamericano, del movimiento policéntrico que estaba teniendo lugar a partir de la transnacionalización de los capitales de origen norteamericano ${ }^{1}$.

El otro punto que corre paralelo al del retorno de la hegemonía

IPara lo que consideramos las caracteristicas esenciales de ese movimiento de transnacionalización ver Gilpin (1975) y M. C. Tavares y A. Teixeira (1981). 
norteamericana pero que es de naturaleza más profunda y cuyas tendencias todavía no están claras, se refiere a la tendencia a una nueva división internacional del trabajo, en la que los EE. UU. pasarían a ser una potencia verdaderamente céntrica, capaz de reordenar la economía mundial, con base en un nuevo tipo de transnacionalización de su propia economía nacional.

Hasta hace muy poco no exa razonable suponer que los EE. UU. conseguirían reafirmar su hegemonía sobre sus competidores occidentales y mucho menos intentar transitar hacia un nuevo orden económico internacional y hacia una nueva división del trabajo bajo su comando. Hoy esa posibilidad es bastante alta.

Hasta fines de la década del 70 no era previsible que los EE. UU. fuesen capaces de encuadrar a los paises que tenían una importancia estratégica en el sistema capitalista: el Japón y Alemania Occidental. Si los EE. UU. no hubieren conseguido someter a la economfa privada japonesa a su juego de intereses y si las políticas inglesa y alemana no fuesen tan conservadoras, los EE. UU. habrían enfrentado dos bloques con pretensiones de independencia económica, uno eiropeo y otro asiático.

Es necesario destacar que, a aquella altura, los intereses en juego eran tan visiblemente contradictorios, que las tendencias mundiales eran policéntricas y parecía imposible que los $\mathrm{EE}$. UU. conseguirían reafirmar su hegemonia, aunque continuase siendo la potencia dominante.

Otras circunstancias generales que se tornaron manifiestas en la década del 70 parecían contribuir a sustentar esta tesis. El sistema bancario privado operaba totalmente fuera del control de los bancos centrales, en particular de la Reserva Federal de los EE. UU.

El subsistema de las filiales de las transnacionales determinó el surgimiento de sistemas de división regional del trabajo a nivel intrafirma, la rebeldía de los intereses nacionales norteamericanos, y un aumento de la competencia en el interior de los demás países capitalistas, que era favorable a la modernización y expansión europea y japonesa y desfavorable a los EE. UU. En síntesis, la existencia de una economía mundial sin polo hegemónico estaba llevando a la desestructuración del orden vigente en la postguerra y a la descentralización de los intereses privados y regionales.

Los desdoblamientos de la política económica interna y externa de los EE. vu., de 1979 hasta ahora, fueron en el sentido de revertir estas tendencias y retomar el control financiero internacional a tra. vés de la llamada diplomacia del dólar fuerte. Ésta, como se verá, a pesar de precipitar al mundo en una recesión generalizada, dio a los EE. UU. la capacidad de retomar la iniciativa. Así hoy, más que nunca, los destinos de la economía mundial se encuentran en la dependencia de las acciones de la potencia hegemónica. 


\section{La diplomacia del dólar fuerte.}

El sistema monetario internacional con base en el patrón dólar oro nunca funcionó bien, como tan bien lo previó Triffin (1958). En rigor, después de la etapa de "escasez de dólares", que terminó con la creación del Mercado Común Europeo, el sistema de Bretton Woods sólo se mantuvo en funcionamiento razonable, desde el punto de vista de la balanza de pagos de sus dos principales pafses miembros, porque el bloque europeo consiguió compensar intrarregionalmente las posiciones superavitarias de un conjunto de países con las deficitarias de otros, a través del mercado de euromonedas. Desde el punto de vista del sistema monetario internacional, el dólar sólo fue aceptado como moneda de reserva - a pesar de su nítida tendencia a la desvalorización en la década del sesenta- porque los bancos norteamericanos lo respaldaron y porque los bancos centrales europeos fueron obligados a absorber el exceso de liquidez proven:ente del déficit de la balanza de pagos norteamericana, bajo pena de que se paralizasen sus políticas monetarias ${ }^{2}$. Desde el punto de vista de la valorización patrimonial, sobre todo en tanto que duró el techo de la tasa de interés norteamericano (Regulación Q), todos los agentes norteamericanos en el exterior, en particular sus filiales industriales y bancarias, y los propios bancos centrales europeos, empezaron a usar el euromercado para operaciones de aplicación de corto plazo de sus reservas en dólares. Como contrapartida, la oferta de dólares se amplió y permitió que las empresas y los países deficitarios, primero de Europa y después del resto del mundo, pudiesen usar créditos denominados en dólares mucho más allá de lo que permitía la expansión de la base monetaria de los respectivos países.

Después de 1968, cuando los EE. UU. cambian su política monetaria y Londres corta la convertibilidad de la libra en dólares, el mercado de crédito interbancario se libera enteramente del patrón monetario y de las reservas dólar-oro y pasa a establecer su propio circuito supranacional de crédito, con una liquidez abundante y creciente, enteramente fuera del control de las autoridades monetarias y sin relación aparente con el déficit de la balanza de pagos norteamericano $0^{3}$. El sistema monetario internacional tenía sus días contados y las crisis monetario-cambiarias de 1971 a 1973 sólo consiguieron proclamar oficialmente su muerte. En contrapartida, a la sombra del patrón dólar se había desarrollado -inicialmente a través del movimiento intraeuropeo de comercio, seguido por' la fuga

"Para una visión descriptiva de la Evolución del Sistema Monetario Internacional hasta las crisis recientes ver Moffitt (1983).

3Para una critica interesante a la visión convencional de la balanza de pagos, ver Aliber (1979), particularmente cap. 8 "Dollar and Cocacote are just bandnames". 
de capitales norteamericanos hacia el euromercado- un floreciente mercado privado de crédito que alimentó el último auge de la expansión de la economía mundial que se produce enttre 1973-74.

La especulación en monedas que se desate después de la ruptura del sistema de paridades fijas, vuelve inoperantes los mecanismos de ajuste monetario de la balanza de pagos. Esta nueva situacion de desequilibrio monetario y cambiario, a la cual se agrega el excedente de petrodólares, permite una expansión todavia mayor del mercado interbancario. Éste escapa enteramente al control del núcleo constituido por el oligopolio de los veinte mayores bancos y de las doscientas mayores empresas multinacionales que tenían Londres como mercado principal. Se produce así una expansión adicional del circuito interbancario, al cual se agxegan centenares de bancos menores de las más diversas procedencias que se amparan en los mercados off-shore y en los llamados paraísos fiscales. Los movimientos especulativos de capital, siempre denominados en dólar, dan lugar a un non system que continúa mirando al dólar como moneda de reserva, desestabilizan periódicamente la libra y fortalecen el marco y el yen como monedas internacionales. De este modo, el orden monetario intemacional camina rápidamente hacia el caos, sobre todo después del primer shock del petróleo y de la politica recesiva norteamericana de 1974 .

Las tentativas del FMr para llevar a cabo un nuevo orden monetario internacional que le permitiese operar una canasta de monedas, respaldando los Derechos Especiales de Giro (SDR) - con base en mayores contribuciones de los principales países de moneda reserva- habían sido obstruidas sistemáticamente por los $\mathrm{EE}$. UU. e Inglaterra, encontrando el mismo apoyo en Alemania y Japón. Sin embargo, el volumen de los créditos interbancarios y de la deuda acumulada por los prestatarios del Tercer Mundo y del área socialista, comenzó a agudizar una sensación de "riesgo creciente" por parte de los bancos centrales de países excedentarios o deficitarios. Éstos habían perdido completamente el control de su situación final de balanza de pagos, gracias a los bruscos movimientos de especulación en monedas. Esta situación acabó llevando a la mayoría de los países capitalistas, con la única excepción de los EE. UU. y de Inglaterra, a apoyar las medidas decisivas del Firr en la dirección de un mayor control público del sistema financiero internacional.

En la reunión mundial del FMI de 1979, Mr. Volker, presidente de la Reserva Federal, se retiró ostensivamente, volvió a los EE. UU. y desde allf declaró al mundo que estaba en contra de las propuestas del FMI y de los demás países miembros, que tendían a mantener desvalorizado al dólar y a proponer un nuevo patrón monetario internacional. Volker adujo que el FMI podría proponer lo que desease, pero los EE. vU. no permitirían que el dólar continuase desvalorizado, tal como venfa ocurriendo desde 1971 y en particular. 
después de 1973, con la ruptura del Smithsonian Agreement. A partir de esta rebelión, Volker subió violentamente la tasa de interés interno y declaró que el dólar mantendría su situación de patrón internacional y que la hegemonía de la moneda norteamericana iba a ser restaurada. Esta diplomacia del dólar fuerte significó que los EE. UU. se sumergiesen a sí mismos y a la economía mundial en una recesión continua durante tres años. Inclusive quebraron varias empresas grandes y algunos bancos norteamericanos, además de someter a la propia economía a una violenta tensión estructural. El inicio de la recesión norteamericana y la violenta alza de la tasa de interés pesaron decisivamente en la derrota popular de Carter. Además de eso, llevaron al borde de la bancarrota a los países deudores, y forzaron a los demás países capitalistas a un ajuste recesivo, sincronizado con la política norteamericana.

Por otro lado, al mantener una política monetaria dura y forzar una supervalorización del dólar, la Reserva Federal retomó en la práctica el control de sus propios bancos y del resto del sistema bancario internacional y articuló en su provecho los intereses del rebaño disperso. De hecho, ese sistema, a partir de la rebelión de Volker, seguido de la quiebra de Polonia, fue obligado en primer lugar a contraer el crédito casi instantáneamente, disminuyendo el ritmo de las operaciones en el mercado intrabancario. Esto sólo se mantuvo sin quiebras más significativas gracias a la sustitución drástica de posiciones, ocupadas rápidamente por los bancos norteamericanos ${ }^{4}$. La reducción de los empréstitos fue aún más violenta, sobre todo para los paises de la periferia, después de la crisis de México, pues en esa ocasión el sistema bancario privado reaccionó en pánico y se refugió en las grandes plazas financieras. A partir de ahí, el movimiento del crédito interbancario se orientó decisivamente hacia los EE. UU. y el sistema bancario pasó a estar bajo el control de la política monetaria de la Reserva Federal, que dicta las reglas del juego. Las fluctuaciones de la tasa de interés y de cambio quedaron nuevamente amarradas al dólar y a través de ellas el movimiento de la liquidez internacional fue puesto al servicio de la política fiscal norteamericana. A partir de principios de los 80, todos los grandes bancos internacionales están en Nueva York, no sólo bajo el paraguas de la Reserva Federal, sino también financiando obligatoriamente -porque no hay otra alternativa- el déficit fiscal norteamericano.

Todo eso puede parecer extraño. Mas la verdad es que hoy presenciamos la siguiente situación: los EE. UU. presentan un déficit fiscal de naturaleza estructural, cuya incomprensibilidad se deriva

${ }^{4}$ Los bancos americanos que posefan en 1980 cerca del $17 \%$ de los flujos brutos de empréstitos bancarios internacionales, llegaron a casi $93 \%$ del total en el Primer Semestre de 1982, antes de la crisis mexicana (datos del BIS extraldos del I. F. Survey 18, dic. 82), citados en Samuel Lichtensztejn, América Latina en la Dinámica de la Crisis Financiera Internacional. 
de la propia polftica financiera y de la política armamentista, ambas agresivas e "imperiales". El componente financiero del déficit es creciente gracias al mero rodaje de la deuda pública, que hizo que ella se duplicase en sólo tres años. La deuda pública americana alcanzó en mayo de 1985 a cerca de un millón y 600 mil millones de dólares, cifra que corresponde a cerca del $80 \%$ de la circulación monetaria global en el mercado interbancario internacional. Esta deuda es el único instrumento que tienen los EE. UU. para realizar una captación forzada de la liquidez internacional y para canalizar el movimiento del capital bancario japonés y europeo para el mercado monetario norteamericano. Por otro lado, es un instrumento de aplicación seguro y de alta rentabilidad para el exceso de recursos financieros de los principales rentistas a escala mundial. Así, a pesar de las críticas al déficit norteamericano, éste se tornó en la práctica el único elemento de estabilización temporal del mercado monetario y de crédito internacional. El precio de esta "estabilidad", ha sido la sumisión de los demás países a la diplomacia del dólar y el ajuste progresivo de sus políticas económicas al desideratum del "equilibrio global del sistema". Evidentemente ese ajuste no se hace sin resistencias.

Hasta 1981 solamente la política económica de Inglaterra apoyaba declaradamente la moneda norteamericana. Los japoneses mantuvieron posibilidades reales de hacer una política monetaria autónoma con bajas tasas de interés, gracias a las peculiaridades de su sistema nacional de crédito y resistieron la adopción de políticas neoconservadoras apoyadas en el recetario monetarista, en cuanto su sistema financiero no se internacionalizó. Varios otros países, como Francia, Austria, los del Norte de Europa y hasta el mismo Brasil intentaron, cada uno a su manera, resistir el alineamiento automático de la política económica ortodoxa. De 1979 a 1981, todos tuvieron claro que no debían alinearse, pero a pesar de eso fueron siendo sometidos. Todos los países desarrollados del mundo, cualesquiera sean sus gobiernos - socialistas, socialdemócratas, conservadores, etc- - están prácticamente alineados en términos de las políticas cambiaria, de tasas de interés, monetaria y fiscal. El resultado de este movimiento es que el espectro de las tasas de crecimiento, de cambio y de interés pasó a ser concéntrico al desempeño de estas variables en el ámbito de la economía americana.

El "equilibrio macroeconómico" de la economía munclial, dada la dolarización generalizada del sistema de crédito, obliga a la mayoría de los países a practicar políticas monetarias y fiscales restrictivas y obtener superávit comerciales crecientes para compensar la situación deficitaria global de la potencia hegemón:ca. Estas políticas, a su vez, esterilizan el potencial de crecimiento endógeno de las economías nacionales y convierten los déficit públicos en déficit financieros estructurales, inútiles para una politica de reactivación económica de corte keynesiano. 
Una experiencia impresionante de alineamiento a las nuevas circunstancias ocurrió con el Japón. Este país, durante toda la postguerra, fue el más heterodoxo en materia financiera y el más autónomo en términos de desarrollo económico. Hizo inversiones con crédito de corto plazo y usó una política monetaria suelta, su sistema comercial lo conglomeró con una estructura de riesgo aparentemente imposib̆le, hizo poco uso del mercado de acciones y de la deuda pública; en fin, produjo su propio modelo nacional de desarrollo. En 1975 intentó un plano de ajuste interno ajustado con las restricciones externas, pero se vio progresivamente forzado a echar mano de su enorme potencial de crecimiento endógeno, en la medida en que su sistema financiero se internacionalizó. El Japón no está hoy haciendo una política activa de desarrollo interno que corresponde a su potencial de acumulación. Salvo en materia de seguridad mínima para su sociedad y de modernización tecnológica no ha mantenido una tasa de inversión elevada correspondiente a su tasa de ahorro interno. Además, está con la mayor parte de su capital bancario y multinacional atado a los proyectos de recuperación norteamericana, con excedentes exportables gigantescos, sin posibilidad de retomar su tasa de inversión y de crecimiento históricas. Eso significa que el mercado financiero japonés está irremediablemente atado al norteamericano, salvo un posible accidente en su trayecto, lo que haría que el sistema norteamericano entrara en turbulencia y el dólar se desvalorizara bruscamente. Este es, mejor dicho, el único punto que todavía puede dar lugar a una ruptura capaz de desestabilizar temporalmente la hegemonía norteamericana.

La diplomacia del dólar ya cumplió su papel, saldando los intereses del capital financiero internacional, bajo comando norteamericano. Aunque la desvalorización del dólar fuese a provocar una nueva crisis financiera internacional, los EE. uU. no perderán el papel rector en la restructuración de un posible "nuevo orden finanlciero internacional".

Hay una diferencia crucial entre la crisis financiera de comienzo de los años 80 y esta que puede diseñarse en el horizonte. Una cosa es impedir, en los activos del sistema bancario internacional, deudas denominadas en dólar de empresas y gobiernos débiles. Otra cosa completamente distinta es impedir en los portafolios de los bancos sumas considerables de la deuda del Tesoro norteamericano.

Fue la amenaza de ruptura del sistema privado de crédito por default de los países periféricos y de algunas grandes empresas lo que colocó bajo el control del sistema bancario norteamericano, y en última instancia de la Reserva Federal, al sistema financiero internacional. ¿Quién pagará sin embargo la deuda externa norteamericana, que hoy es superior a la del conjunto de América Latina? $\mathrm{Y}$ si ella se desvaloriza bruscamente, ¿quién va a perder? 


\section{El retorno al crecimiento y la propuesta hegemónica.}

Hace algún tiempo, todo llevaba a creer que los EE. UU. habían perdido la capacidad de liderar la economía mundial de una manera benéfica. Eso continúa siendo verdad. Pero por otro lado, es indiscutible que los norteamericanos dieron, entre 1979 y ،1989, una demostración de su capacidad maléfica de ejercer su hegemonía y de ajustar a todos los países, a través de la recesión, a su desideratum. Y, claro está, lo hicieron con una arrogancia y una violencia sin precedentes.

A partir de 1982 procedieron a su propia recuperación de crecimiento. Esta recuperación tiene aspectos controvertidos, tanto por su posible duración como sobre todo por la forma en que fue financiada.

Un primer hecho que debe destacarse es que la recuperación de la economfa norteamericana fue hecha con crédito de corto plazo y con creciente endeudamiento. En la práctica los norteamericanos están aplicando la misma técnica que Brasil y México aplicaron recientemente y que Japón utilizó en la década de los 50 . Finalmente, los EE. UU. descubrieron la técnica latinoamericana y japonesa de desarrollo: financiamiento del crecimiento con base en crédito de corto plazo, endeudamiento externo y déficit fiscal. Y como su moneda es hegemónica y sobrevalorizada, la economia norteamericana no tiene inflación. Este es un hecho que deja espantados a los economistas, pues si valiese lo que desean los monetaristas o los keynesianos, o cualquier libro de texto tradicional, los EE. UU. ya habrian experimentado una inflación galopante en virtud del fantástico empuje de demanda promovido por la técnica heterodoxa de la política económica.

Un ejemplo de esta heterodoxia dice respecto a la politica presupuestaria. Los EE. UU. prácticamente estancaron el gasto en bienes y servicios de utilidad pública, aumentaron el gasto del welfare. En síntesis, cambiaron los gastos en el capital social básico y el bienestar social por armas e hicieron una redistribución de rentas en favor de los ricos. Además, redujeron la carga tributaria sobre la clase media y prácticamente eliminaron la incidencia de impuestos sobre los pagos de intereses a los bancos para compras de consumo durable. Propiciaron también depreciaciones aceleradas de activos y el refinanciamiento de pasivos de ciertas firmas. En estas circunstancias, el endeudamiento de las familias pasa a ser un excelente negocio, porque parte de la carga financiera de la deuda es descontada en el impuesto a la renta. Así, se tomó crédito de corto plazo en gran escala para apoyar la compra de casas y bienes de consumo durables. Además, financiaron inversiones, en el terciario y en las industrias de alta tecnología, que no requieren un período de maduración muy largo y cuya tasa de rentabilidad esperada 
es muy superior a la tasa de interés nominal, en declinación. Este descenso de la tasa nominal de interés se debe aparentemente a tres motivos entremezclados: la absorción de liquidez internacional, la posición menos ortodoxa de la Reserva Federal y la caída de la inflación. Esta última, a su vez, se debe a la baja de costos internos provocada por la sobrevalorización del dólar y por la concurrencia de las importaciones, acarreando una mejoría en las relaciones de intercambio favorables al poder de compra de los salarios.

Otro punto que se debe aclarar se refiere a la influencia de la tasa de interés sobre la inversión. Mucha gente afirma que el elevado nivel de la tasa de interés reai se va a terminar, tarde o temprano, frenando el gasto en inversión. Conviene advertir que los norteamericanos no están financiando la inversión a través del mercado de capitales. No hay mercado de capitales nuevos; el mercado relevante hoy es el monetario o el de crédito de corto plazo. Los norteamericanos están sustituyendo el tradicional endeudamiento de largo plazo (a través de la emisión de obligaciones o bonos, activos netos, etc.) por crédito de corto plazo, o utilizando recursos propios y capital de riesgo externo. Por otro lado, está claro que esta situación coloca en difíciles condiciones a muchas compañías viejas o endeudadas y el valor de sus respectivas acciones y bonos. Si una gran compañía quisiera lanzar, como varios trataron de hacer recientemente, alrededor de mil millones en papeles en el mercado de bonos, en una semana esta misma compañía estaría obligada a recomprarlos, pues en caso contrario, ciertamente corría el valor de las acciones. Vale decir, el único riesgo real que los EE. UU. están corriendo es el de sufrir una desvalorización brutal de las antiguas empresas cuyas acciones estén cotizadas a un valor distinto del efectitvo. Dígase de paso que todos los grandes bancos que hicieron inversiones en los ramos productivos "tradicionales", como en energía y agricultura, esto es, sectores que requieren crédito de largo plazo y/o tasas de interés más bajas, pasaron, y todavía pasan, por serios problemas. La quiebra técnica del Continental Illinois es un ejemplo claro de esto. Por otra parte, todos aquellos que invirtieron en California, en Silicon Valley, en los servicios, están en una situación extremadamente favorable.

$U_{n}$ tercer aspecto fundamental de ese proceso de restauración de Ia posición hegemónica de los EE. UU. se hace evidente cuando analizamos sus relaciones económicas internacionales. Entre 1982 y 1984, los EE. UU. consiguieron duplicar su déficit comercial cada año, lo que juntamente con la recepción de intereses les permitió absorber transferencias reales de ahorro del resto del mundo, que sólo en 1983 correspondieron a 100 mil millones de dólares y en 1984 deben haber traspasado los 150 mil millones. Por otro lado, mejoraron sus relaciones de intercambio y cayeron sus costos internos, ya que las importaciones que Ios EE. UU. están haciendo son las mejo- 
res y las más baratas del mundo entero. Así, sin hacer un esfuerzo intensivo de ahorro e inversión, sin tocar en su infraestructura energética y de transportes, ni la agricultura, ni la antigua industria pesada, los EE. UU. están modernizando su industria de punta con equipos baratos de mala calidad y capitales de empréstito y de riego de Japón, de Alemania, del resto de Europa e incluso del mundo periférico.

Muchos esperaban que a partir de 1983, Ios EE. UU. reverterian. la posición superavitaria final de la balanza de pagos, pues desde 1982 las rentas de capitales norteamericanos en el exterior no están cubriendo el déficit norteamericano en transacciones corrientes ${ }^{5}$.

Pero eso no ocurrió porque las entradas de capital bancario se encargaron de efectuar ampliamente esta cobertura ${ }^{6}$. La inversión en capital de riesgo también se ha mantenido elevada desce 1981, superior en una media de us\$17 mil millones. Solamente el Japón, por ejemplo, invirtió diez mil millones de dólares en el período de recuperación y ya proyectó invertir $40 \mathrm{mil}$ millones hasta fines de la década. Por su lado, Alemania debe haber invertido alrededor de 8 a 9 mil millones, si bien no tenemos datos precisos sobre el monto. En suma, toda Europa y Japón están invirtiendo en los EE. UU. en cuanto estos últimos hicieron retornar parte de los capitales de las filiales de multinacionales norteamericanas que no tienen capacidad de expansión adicional en el resto del mundo. En último término, mientras la periferia está prácticamente estancada y el resto del mundo crece a 1 ó $2 \%$, los eE.uU. estuvieron creciendo a una tasa de 6 a $8 \%$ en los dos últimos años.

Apoyados en un enorme flujo de capitales que superó los 100 mil millones de dólares en 1984, los EE. UU. pudieron mantener y ampliar una brecha comercial cuyos límites no son todavía visibles. De 30 mil millones en 1982 pasó a 60 mil millones en 1983 y saltó a más de 120 mil millones en 1984. En 1985. podría continuar aumentando si no fuese por la desaceleración de la economía norteamericana, simplemente porque hay capital sobrante en el mundo. Y este exceso de capital y de "ahorro externo" se debe a que el resto del mundo obedeció a la política conservadora, fuese cual fuere el tipo de gobierno. En verdad, la sincronización de las políticas ortodoxas obligaron a todos los países a mantener sus tasas de inversión y crecimiento en niveles bajos y a forzar las exportaciones. Gomo un reflejo del ajuste forzado, casi todos los países del mundo están experimentando superávit en la balanza comercial. Todos menos uno, los EE. UU. Ellos abren su economía y al hacerlo provocan una gran transferencia de renta y de capitales del resto del mundo.

Ver tabla 1 The us Current Account.

Ver tabla 2 United States Capital Account. 
Un aspecto muy importante es que esto permite terminar el déficit estructural financiero del sector público. Todo sucede como si cada vez que la Reserva Federal coloca títulos de la deuda pública en el mercado, tuviese la certeza de que los títulos serán colocados en todas las estructuras bancarias y junto a todos los rentistas de paises desarrollados, o not. El hecho esencial es que todo el mundo está financiando no sólo el Tesoro de los EE. UU., especialmente su componente financiero, sino además los consumidores e inversionistas norteamericanos. Contrariamente a la década del 70, esta vez hubo una transferencia de "ahorro real" y no sólo de crédito, liquidez o capital especulativo.

En estas condiciones, los EE. UU. no precisan resolver internamente su problema de financiamiento fiscal y por lo tanto dejaron de presionar la tasa de interés, que puede caer, siendo suficiente mantener un ligero diferencial sobre las tasas del euromercado.

En cuanto a que la tasa de crecimiento de la economfa mundial fue inferior a la tasa de crecimiento norteamericana no hay la menor posibilidad de que los capitales excedentes, sobre todo los bancarios y los de las empresas con capacidad ociosa, resuelven invertir preferencialmente en sus países de origen.

Desde el ajuste recesivo, los países europeos no han formulado un plan para restaurar sólidamente su crecimiento económico global. Sólo intentaron individualmente la modernización de ciertas industrias e intentaron protegerse para que el Japón no invadiese sus mercados. Pero al mismo tiempo en que la competencia intercapitalista se acentúa, en el resto del mundo se opera un fantástico aumento de la eficiencia de las industrias modernas en el Japón Y en algunos países de Europa. Como ya vimos, los EE. UU. están aprovechando esta situación para modernizar su estructura productiva, a costa del resto del mundo, inclusive de la periferia latinoamericana, que ya transfirió en los últimos años casi 100 mil millones de dólares a partir de los superávit comerciales crecientes y de una pérdida de sus relaciones de intercambio.

A partir de 1984 la economía mundial se recuperó con la contribución decisiva del crecimiento de las importaciones norteamericanas. Estas alcanzaron tasas de expansión sin precedentes y beneficiaron indiscriminadamente todas las áreas: el Japón y Canadá, por su posición particular en el comercio norteamericano, recibieron un $23 \%$ de incremento global de los últimos dos años; Europa, como un todo, recibió un monto equivalente y los paises en desarrollo poco más de un $26 \%$.

TEI Segundo Semestre de 1984 las compras externas lfquidas de tftulos del Tesoro Americano fueron superiores a Us $\$ 20$ mil millones. Ver O.E.c.D., Economic Outlook, junio 1985, p. 60.

SVer tabla 3, Shere of the increase in us imports. 
La opinión "bien informada", eufórica con esta situación, comenzó a considerar a los EE. UU. como un trade locomotive de la recuperación mundial y la élite financiera norteamericana propuso al mundo una nueva división internacional del trabajo, en la cual la economía norteamericana desempeñaría un papel dominante. Ella se comprometería a no bajar unilateralmente el déficit comercial, pero respondería con represalias a los países que aplicasen restricciones a las exportaciones de mercaderías y capitales norteamericanos.

Conviene transcribir los siguientes pasajes escritos por dos miembros del directorio del Morgan pertenecientes a la Comisión sobre Competitividad Industrial nombrada por el Presidente Reagan, que a nuestro juicio expresa bien la propuesta hegemónica ${ }^{9}$.

"El déficit comercial de los EE. UU. se iguala a la fuerza de la inversión en la economía norteamericana en medio de una relativa escasez de ahorros internos ... Sería posible disminuir el déficit comercial de los EE. UU. recortando la inversión norteamericana y retardando el crecimiento económico. Sin embargo, esta es una fórmula segura para un estancamiento mundial. Mucho más constructiva sería una estrategia para la competitividad de los EE. Uu. que mantiene fuerte a la economía norteamericana, fomenta el ahorro interno y ampara un clima positivo de inversión en el exterior, especialmente en Europa y América Latina...".

En lo que se refiere a los efectos del déficit sobre el empleo y la competitividad industrial, el documento hace los siguientes comentarios:

"El déficit comercial desplaza los puestos de trabajo norteamericanos de los sectores competitivos de exportaciones e importaciones hacia aquellas actividades que están menos expuestas a la competencia internacional, especialmente hacia los servicios. El efecto neto de este desplazamiento de empleos no está claro y puede no ser perjudicial para el interés nacional de largo plazo. La tolerancia del déficit comercial y la fortaleza dèl dólar mantiene alta la presión sobre las industrias domésticas a fin de que eleven la productividad y restrinjan los aumentos de costos. Más aún, las presiones del comercio apresuran el reemplazo de industrias anticuadas por empresas avanzadas...".

En lo que se refiere al papel global de la política comercial norteamericana:

"El sistema comercial de postguerra fue designado en primer lugar para dirigir el comercio internacional del comercio de los EE.UU. y Europa, cuyas filosofías de manejo económico tienen mucho en

${ }^{3}$ Las citas que siguen fueron extraidas del artfculo de fondo "Strengthening us competitveness", del World Financial Markets, Morgan Guaranty Trust Company, New York, septiembre 1984. 
común... Hoy, los intereses han variado. Los Ee. uU. miran no sólo hacia Europa en su comercio externo y sus intereses de seguridad, sino también al Japón, los Países en Rápida Industrialización (NIc's) y América Latina...".

En lo que se refiere a los países menos desarrollados y hablando en nombre de los desarrollados, la dureza de posiciones y del carácter impositivo son manifiestos:

"Sin embargo, los países industriales maduros no aceptarán más especialización en alta tecnología, comunicaciones y actividades de servicios a no ser que los paf́ses menos desarrollados ofrezcan significativas concesiones. Ellos esperan que éstas abran sus mercados a productos industriales avanzados y a la tecnología importada. También deben mantener un código de conducta explícito que regule la inversión privada directa, los componentes domésticos asociados con ellas y sus requerimientos en materia de exportaciones. En particular, los NIG's, que están avanzando rápidamente, deberán renunciar a las excepciones existentes en ciertas obligaciones de la GATT, con el pretexto obsoleto de las necesidades de la balanza de pagos...".

Entretanto, el mayor grado de apertura de la economfa norteamericana a las importaciones y al capital extranjero encuentra serias resistencias en los sectores afectados, que claman por un mayor proteccionismo. El liderazgo de la clase financiera norteamericana está contra el proteccionismo e intenta defenderse, enfatizando dos aspectos fundamentales: negociaciones con sus áreas de influencia y represalias contra los proteccionistas externos.

"Las negociaciones tendientes a un acuerdo de libre comercio con Israel; la sugestión de un acuerdo más limitado con Canadá; y conversaciones sobre una apertura más amplia hacia la Cuenca del Pacífico, incluyendo el Japón, los NIc's de Asia y México, como también Ganadá...".

"En el esfuerzo para forzar una apertura de los mercados externos que están cerrados a los exportadores de los EE. UU., la herramienta de negociación disponible más potente que posee los EE. UU. es la amenaza de limitar el acceso externo a los amplios mercados norteamericanos ...".

Como se puede ver, este es un conjunto de argumentaciones coherentes, que pretenden mantener un relativo "equilibr:o macroeconómico" entre los participantes más importantes de la economía raundial. Pero el tono racional no disfraza el "big stick" en relación a los países periféricos, ni el desideratum estratég.co de mantener y afirmar la Hegemonía Norteamericana en términos globales.

EI mensaje en relación a Europa es de dos naturalezas. La primera se refiere al comercio multilateral.

"Tarde o temprano no hay una sustitución adecuada para las ne-

$$
\left[\begin{array}{lll}
4 & 9 & 0
\end{array}\right]
$$


gociaciones globales, en particular para obtener que Europa se comprometa totalmente".

La segunda, propone recomendaciones para la restauración del dinamismo europeo. El diagnóstico es sumario:

"Actualmente Europa sufre de altos impuestos, regulaciones inestables, costos laborales inflexibles y barreras a la movilidad".

Las recomendaciones siguen en la línea del neoliberalismo norteamericano, que aparentemente es muy apreciado, como se ve en las últimas reuniones de la cumbre europea:

"Europa ha perdido con razón la fe en el gasto público como un estímulo para el crecimiento. Pero su énfasis en disminuir el déficit fiscal no es una fórmula suficiente para impulsar el crecimiento, puesto que presume que la inversión va a sustituir espontánea $y$ suficientemente al consumo público y privado ... La experiencia de los EE. UU. sugiere fuertemente que, en materia fiscal, la necesidad prioritaria de Europa es que se hagan disminuciones de impuestos orientadas a incentivar, que es el medio más efectivo para estimular la inversión y el empleo...".

Finalmente, para no dejar a nadie atrás, también hay una advertencia para el Japón:

"Si bien su dinamismo en tecnología y productividad es ampliamente admirado, la infraestructura física del Japón difícilmente tiene paralelo con su destreza industrial. Se hace sentir ampliamente la necesidad de invertir en viviendas. caminos, sistemas de alcantarillado y conservación del medio ambiente...".

Conviene ahora hacer algunas consideraciones finales sobre la peculiar situación de la economía norteamericana y su cambio de posición en la economía internacional.

La estructura de comercio norteamericana fue tradicionalmente simétrica y cerrada. Los EE. UU. exportaban e importaban materias primas, alimentos, insumos industriales y bienes de capital; en fin, todos los ítemes importantes del comercio internacional. Las relaciones económicas de los EE. UU. con el resto del mundo no podían ser encuadradas dentro del tradicional esquema centro-periferia. Los EE. UU. no precisaban de una división internacional del trabajo que los favoreciese en términos absolutos o relativos. El hecho sorprendente es que ahora están, aparentemente, queriendo instaurar una división internacional del trabajo en la cual desempeñarian un papel céntrico, para el que están dispuestos a abrir su economía. El actual déficit comercial ya representa un $3 \%$ del $2 N B$ norteamericano y a partir de finales de 1984 los EE. vu. pasaron a ser un deudor l'quido en el mundo, esto es, revirtieron su posición de más de sesenta años de exportadores líquidos de capitales y en sólo tres años se convirtieron en deudores ĺqquidos del resto del mundo. 
Después de haber exportado durante varias décadas, el patrón tecnológico del sistema industrial norteamericano a través de sus multinacionales está intentando usar su poder hegemónico para reencuadrarlas, hacer retornar sus capitales sobrantes y rehacer su posición como centro tecnológico dominante. Utilizan, de este modo, sus bancos, el comercio, las finanzas y la inversión directa extranjera para hacer su ajuste interno $y$ externo ${ }^{10}$. A pesar de haber perdido la competencia comercial para las demás economías avanzadas, e incluso algunas semindustrializadas, en los productos de tecnologí de uso difundido, los $\mathrm{EE}$. UU, están ahora invirtiendo fuertemente en el sector terciario y en las nuevas industrias de tecnología de punta, en la cual esperan tener ventajas comparativas. Los EE. UU. no parecen interesados en sustentar su antigua estructura productiva comercial. Saben también que no tienen la capacidad de alcanzar un enorme auge a partir de reformas en los sectores industriales que lideran el crecimiento económico-mundial en la postguerra. AI contrario, los EE. UU. están concentrando esfuerzos en el desarrollo de los sectores de punta y sometiendo la antigua industria a la competencia internacional de sus socios. A partir de esa modernización generalizada esperan poder retomar su posición como centro tecnológico dominante y reordenar de nuevo la economía mundial.

Con sus enormes déficit comerciales, han garantizado la solidaridad de sus principales socios exportadores, sobre todo el Canadá, Japón y los NIc's asiáticos. Con sus altas tasas de interés real, han garantizado la solidaridad de los banqueros. Y, como las joint ventures dentro de los EE. vu., están intentando garantizar su posición de avance para el futuro.

La respuesta europea y japonesa ha sido hasta ahora forzosamente de "alianza" con los EE. uU., pero su destino de largo plazo como "periferia" del "centro" está por verse.

La arrogancia con que la élite norteamericana trata la política económica europea y considera como área privilegiada de interés a "su base ampliada en el Pacífico", que incluye Canadá, México, Japón y los NIC's asiáticos, debería estar preocupando a Europa. Ésta, en tanto, continúa paralizada por razones de seguridad, por las relaciones estratégicas de alineamiento automático con los EE. UU. por razones de competencia y rivalidad intraeuropea que acarrean la incapacjdad de hacer una política económica común, comenzando por la monetaria. Inglaterra y Alemania, cada una a su manera, jugaron un papel decisivo en la derrota de los proyectos de la socialdemocracia europea y Francia socialista sucumbió melancólicamente en sus proyectos nacionales.

${ }^{10}$ Existen dudas fundadas sobre la naturaleza "extranjera" de ciertos capitales que ingresan en los $\mathrm{EE}$. UU, ya que los mismos no aparecen en las balanzas de pagos de los demás países y la cuenta de Errores y Omisiones en el balance norteamericano es gigantesco. 
En ausencia de una relación real, las racionalizaciones comienzan a aparecer y la respuesta europea ha sido la de aceptación progresiva de la ideología neoliberal y no de hacer avanzar el "espiritu de cooperación y planeamiento" que presidió el surgimiento del Mercado Común.

\section{Las nuevas tendencias económicas internacionales}

Cualquier proyección macroeconómica efectuada por los distintos organismos internacionales, como el BIRF, el FMI o la OCDE, reconoce que los Estados Unidos continuarán manteniendo una economía deficitaria por los próximos años y que el Japón será estructuralmente superhabitario. Reconocen también que el conjunto de los países europeos tenderá a mantener entre sí relaciones que, aunque de menor dinamismo, continuarán produciendo un relativo equilibrio intraeuropeo en los movimientos de capitales, no obstante que tenderán a ser globalmente superhabitarios en materia comercial, siempre que su tasa media de crecimiento sea inferior a la de los EE.UU., como ha sido en los últimos años. Las proyecciones hasta 1986/ 1988 apuntan hacia una continuidad en la tendencia al menor crecimiento relativo de Europa, con tasas moderadas de inversión, de consumo y de empleo, si bien con un crecimiento razonable de la productividad. Para los EE. UU. $\checkmark$ el Japón las proyecciones indican tasas más altas y semejantes de crecimiento de la inversión y del consumo, pero ligeramente superiores en cuanto al ritmo de crecimiento del producto en el caso del Japón, a causa de su comportamiento exportador.

La gran duda que se abate sobre este escenario de "optimismo moderado" consiste en que la inestabilidad de la economía norteamericana no permita un "soft-landing". El excesivo endeudamien. to de los EE. UU. Y la reciente desaceleración de su crecimiento podrían provocar una desvalorización muy brusca del dólar que conduzca a una fuga de capitales y torne inmanejable la situación de balanza de pagos norteamericana. Esto podría inducir a las autoridades monetarias de los EE. UU. a ensavar una nueva respuesta recesiva de carácter deliberado. A través de un nuevo estímulo a la liquidez financiera y de una nueva alza de las tasas de interés, la Reserva Federal podría intentar una vez más poner en práctica una diplomacia basada en un dólar fuerte y provocar un "hard-landin e" de la reciente recuperación norteamericana y mundial.

La mayoría de los organismos internacionales ponen énfasis en la incapacidad que enfrentarían Ios EE. UU. a mediano plazo para servir su deuda externa. Según ellos, la tasa de ahorro interno en ese pais es muy baja y la inversión directa extranjera no genera incrementos de productividad suficiente en sus sectores exportadores como para servir el enorme monto de la deuda acumulada en los últimos años. 
Conviene separar los argumentos que tienden a confundir el ahorro con la deuda y la liquidez con el capital, argumentos que se encuentran fundados en la visión convencional del "ajuste monetario de la balanza de pago". Examinando con mayor detalle las cuentas externas norteamericanas, queda en claro que estos rubros son de naturaleza diferente y no tienen las mismas implicaciones para el posible pago de la deuda.

Así, por ejemplo, de los 100 mil millones de dólares ingresados por concepto entrada de capitales en 1984, sólo el $40 \%$ corresponde de hecho a un ingreso líqu:do de capitales de largo plazo, y de ellos la mitad tomó la forma de adquisición de títulos de la Tesorería norteamericana ${ }^{11}$. Vale decir que el grueso de la entrada de capitales es eminentemente financiera, especulativa y de corto plazo. Por tanto, los EE. UU. aparentemente estarían en la misma situación que América Latina, que se financió con endeudamiento a corto plazo y en la actualidad no está en condiciones de servirla. Sin embargo, la semejanza es sólo aparente, ya que los EE. Uu. son el país emisor de la moneda en la cual está expresada la deuda $y$, por lo tanto, no corre ningún riesgo de crisis de liquidez o de insolvencia. Solamente corre un riesgo inflacionario, lo que desvalorizaría la deuda y dejaría en mala posición a los acreedores, y no al país deudor, en última instancia ${ }^{12}$.

Ya el total de la inversión extranjera directa en 1984 fue del orden de los 15 mil millones de dólares, lo que equivale a sólo el 10\% del total de los gastos en inversiones residenciales y a solamente el $3,7 \%$ de la inversión fija bruta de carácter no residencial. Conviene recordar, sin embargo, que esas nuevas inversiones extranjeras se dirigieron a nuevas áreas con tecnología de punta e implicaron una movilización adicional de recursos locales, y no representan una sustitución de "ahorro interno" por "ahorro externo" como ocurre con los demás saldos financieros de la balanza de pagos. Debe recordarse también que el grueso de la inversión norteamericana continúa dependiendo, sobre todo, de los márgenes de rentabilidad de sus empresas productivas y de la situación de los negocios en el plano de su economía interna. Así, la recuperación de la economía norteamericana, producida por la expansión del consumo, las utilidades de las empresas y la ocupación de la capacidad instalada de la industria, los que permitieron la recuperación de los niveles de inversión global y su continuo crecimiento desde 1982 hasta 198413. Las perspectivas de aquí en adelante, sin embargo, son menos cla-

"ver datos de "Economic Outlook" de la O.E.c.D., pp. 59-60, junio de 1985.

${ }^{12}$ En términos de balanza de pagos, todo dependerfa de cómo se registrasen los movimientos de capital desde el punto de vista del ajuste compensatorio, para servir la deuda, pero el efecto no sería una pérdida de ingreso real para la economía norteamericana, como en el caso de América Latina.

${ }^{13}$ Ver Survey of Current Business No 2, febrero de 1985. 
María da Conceição Tavares / La recuperación de la hegemonia...

ras y dependen menos de la balanza de pagos que de las variables internas de la economía norteamericana.

Por lo tanto, debemos reconocer una posible asimetría entre el comportamiento de la balanza comercial y del balance de capitales norteamericanos, que podría alterar las proyecciones a mediano plazo de los principales organismos internacionales.

En verdad, la evolución de la balanza comercial norteamericana en el futuro depende fundamentalmente del ritmo de crecimiento de la inversión interna. Dado que el $50 \%$ de crecimiento de las importaciones entre 1981 y 1984 se debió a importaciones de maquinarias y equipos de transporte (ver tabla 4), las tendencias recientes hacia la rápida desaceleración de la economía norteamericana deben reducir sustancialmente su déficit comercial. Así, aunque la sobrevalorización del dólar se mantenga, no es probable que las tendencias hacia el aumento del déficit comercial externo sean las previstas por las proyecciones internacionales para los próximos años. Esto significa, desde luego, que el impacto de la "locomotora co" mercial" sobre la economía mundial tenderá a frenarse, y que la irradiación del comercio de los EE. UU. se centrará en sus áreas preferenciales, a saber, la que ellos mismos denominan la "cuenca ampliada del Pacífico".

Un problema más grave aún para la economía mundial podría surgir si el dólar, a ejemplo de lo ya ocurrido en junio de 1985, sufriera una desvalorización aún más brusca a causa de las expectativas altamente especulativas de los mercados financieros internacionales. Lo que en ese caso estaría en tela de juicio sería el balance de capitales norteamericanos a corto plazo, con la posibilidad de bruscas fluctuaciones en los movimientos de capital bancario. En tal situación, no habría que descartar la posibilidad de reacciones defensivas de las autoridades norteamericanas o posibles pérdidas patrimoniales de los rentistas que han invertido en dólares. En tal caso, serían altamente plausibles nuevas turbulencias en el sistema financiero internacional. Del mismo modo, en este caso las proyecciones "moderadamente optimistas" para los próximos años se verian interrumpidas y las tendencias de corto plazo de la producción y del comercio mundial se tornarian imprevisibles.

Si hacemos abstracción de estas posibles turbulencias en el escenario internacional, una vez más relacionada con el papel del dólar y con el destino del sistema bancario mundial, sería posible vislumbrar algunas tendencias de largo plazo que surgirían de la trayectoria de la economía internacional en este último decenio.

La primera de ellas consiste en que la hegemonía norteamericana no debería sufrir ningún revés serio en lo que dice relación a su poder de "encuadramiento" del resto de las economías, aunque eso 
signifique una serie de recesiones que limiten la recuperación de la economfa mundial a mediano plazo.

La segunda se refiere a la orientación de la economía europea, que afectará a largo plazo las tendencias de la producción y el comercio internacional. En este punto, conviene formular algunas especulaciones vinculadas con las tendencias contradictorias señaladas por diversos informes y pronunciamientos de las autoridades económicas norteamericanas y europeas.

Prácticamente todos están de acuerdo en que el potencial de acumulación y modernización japonés debería continuar y que esa economía insular está fuertemente atraída por la economía norteamericana.

Donde el debate se confunde es con respecto a la posible trayectoria de Europa y de los propios EE. uv. Dicho esto, existe poca discusión sobre la actual periferia del sistema. En particular, sobre América Latina, lo que se discute es el problema de la deuda externa, que continúa pesando en su horizonte de posibilidades, a pesar del gigantesco esfuerzo de ajuste que los países de esta región se han impuesto en los últimos años.

Es posible comprender la escasa atención que ha merecido América Latina, ya que aparentemente su capacidad de ejercer influencia en los destinos de la economía mundial se perdió cuando los países deudores no acompañaron a México en su "default" y no adoptaron, de ahí en adelante, una acción conjunta como deudores. Lo que hoy está en discusión es el destino individual de cada pais y su capacidad de sobrevivencia frente al ajuste recesivo a que han sido forzados. Aún son posibles negociaciones individuales más o menos ventajosas, y la deuda externa latinoamericana aparece hoy risible comparada con la propia deuda norteamericana, desde el punto de vista del porvenir del sistema bancario internacional.

La discusión sobre el futuro de los te. uU. y de Europa ha constituido un tema de debate permanente a ambos lados del Atlántico y aparentemente ni los americanos ni los europeos han alcanzado un consenso sobre sus respectivos destinos. Sobre el debate norteamericano no conviene alargarse, ya que éste es objeto de un trabajo de Fernando Fajnzylber presentado en este mismo informe, con el cual no tengo mayores discrepancias. Sólo quiero agregar algunas observaciones sobre la trayectoria de su crecimiento a largo plazo.

Los problemas estructurales que los EE. UU. aún deben resolver no pueden ser enfrentados a través de la actual intermediación financiera en que el capital bancario especulativo constituye el centro del sistema financiero internacional. El atraso de la economía norteamericana en su infraestructura básica $y$, en particular en los sectores de la minería, los transportes y los servicios de utilidad públi- 
ca queda de manifiesto cuando se mira a los datos sobre inversión recién publicados por el Survey of Current Business ${ }^{14}$.

En el período 1977-83, mientras que la tasa de crecimiento de la capacidad productiva y del equipamiento de la industria manufacturera creció en un promedio del $3 \%$ por año y el sector del comercio y los servicios creció al $4 \%$, el sector de los servicios de utilidad pública creció sólo el 1,5\% y el de los transportes y la minería tuvieron caídas promedias de cerca del $4 \%$ por año.

Evidentemente la reestructuración de estos sectores básicos no podría encararse con deudas y capitales de corto plazo y mucho menos con las actuales tasas de interés a largo plazo. Entretanto, éstas no bajaron gracias a una paulatina reducción del déficit fiscal y ello hace necesario, a nuestro ver, un proceso previo de consolidación, reescalonamiento o desvalorización de la deuda interna norteamericana. Aquf los EE. UU. sufren un problema semejante al latinoamericano, y más particularmente al brasileño, en cuanto su. deuda externa, generada a corto plazo, está siendo un obstáculo central para el financiamiento a largo plazo de las inversiones en infraestructura. Estas últimas no resisten tasas de interés superiores al 2:\% ó 3\% y requieren préstamos con largos períodos de gracia y de maduración. Es de esperar que el gobierno norteamericano o el Banco Mundial tomen alguna providencia en este sentido en vez de esperar que los mercados de capitales de largo plazo vuelvan a los "buenos tiempos de antes", anteriores a la crisis financiera internacional.

Sobre el debate europeo, la cuestión central parece ser la necesidad de superar la "esclerosis europea". Por lo tanto, el debate se ha mantenido a la defensiva. La izquierda europea no quiere aceptar las recomendaciones liberales, pero tampoco da mucho crédito a virtudes del socialismo ni incluso a la "planificación social" europea, y recomienda como panacea la competencia con los EE. UU. en las nuevas tecnologías. ¿Para qué? ipara poder exportar más hacia los propios EE. UU. o para competir con sus vecinos europeos más avanzados!

En cuanto a los conservadores, el argumento tiende a concordar con las recomendaciones norteamericanas. Así por ejemplo, en un reciente artículo, el profesor Marjolin (ex Secretario General de la OCDE, Vicepresidente de la CEE y negociador del Tratado de Roma) dice textualmente:

"La debilidad de Europa ha sido su incapacidad para crear nuevos trabajos".

La razón principal que él apunta para esto es que:

${ }^{14}$ Ver Survey of Current Business, volumen 65, No 2, febrero de 1985, tabla 2, púgina 19. 
"Desde 1973 a 1982 los salarios y los beneficios sociales en términos reales han estado creciendo en forma demasiado rápida. Sin embargo, en los últimos pocos años, se ha logrado un considerable progreso en corregir esto a través de reducciones en los déficit presupuestarios gubernamentales, la disminución del ritmo de aumento de los sueldos y la racionalización de algunas de las industrias más antiguas".

Y más adelante:

"Se acerca el tiempo en que, en orden a estimular una recuperación incipiente, varios países serán capaces de enfrentar reducciones impositivas en una escala moderada mientras crean incentivos a la inversión de varios tipos"15.

Como se ve, se trata de un claro endoso a las posiciones de los "supply-siders" norteamericanos, que refleja una vez más la extensión de la ideología conservadora.

Ya en los informes internacionales supuestamente más objetivos, las conclusiones no son muy optimistas. Así, el último informe de la OCDE, después de un capítulo sobre las incertidumbres actuales, pasa a analizar las tendencias de mediano plazo, llegando a estas conclusiones:

"En forma aún más perturbadora, a pesar del considerable interés y estímulo que ha reinado en Europa en relación con la alta tecnología durante los últimos años, su balanza comercial parece estar afectada por una tendencia declinante de carácter secular. Si estas tendencias continuaran, Europa tendería cada vez más a constituir un abastecedor neto de alimentos y materias primas para el resto del mundo, así como de bienes manufacturados de baja tecnología, áreas donde la competencia proveniente de países no miembros de la oGDE (y de ciertos países de la OCDE no europeos) probablemente llegará a ser más agresiva, especialmente si $\gamma$ cuando las barreras proteccionistas sean desmanteladas ${ }^{16}$.

En resumen, las nuevas tendencias económicas internacionales son inestables y poco optimistas para Europa y para la periferia del mundo capitalista. Son inestables también para los EE. UU. y su nuevo socio, el Japón, pero presentan posibilidades de una articulación hegemónica que podría conducir, a mediano y largo plazo, a una reordenación de la economía mundial. Sobre esta perspectiva, to-

"Ver Robert Marjolin, "Is Europe Suffering from Sclerosis?", en Amex Review, 24 .de junio de 1985.

18OCDE Economic Outlook, junio de 1985, pp. 22-25. 
davía dudosa y de inciertos resultados, se centran las consideraciones finales de este trabajo

\section{4. ¿Un nuevo esquema centroperiferia?}

La nueva división internacional del trabajo que está en discusión pasa por la intensificación de las relaciones económicas entre los EE. UU., el Japón y los NIC's asiáticos ${ }^{17}$. Este reforzamiento de la "Cuenca del Pacífico" serviría como contrapartida a la expansión norteamericana en el Atlántico durante la postguerra y daría finalmente una posición céntrica a la gran potencia americana. Vale decir que el mapa del mundo cambiaría finalmente su configuración estructural, de tal manera que el europeo-centrismo de orígenes históricos desaparecería, y los EE. UU. dejarían de ser una gran potencia "excéntrica". Hacia el final del siglo, la visión geográfica del mapa mundi sería, en forma generalizada, la que ya hoy es posible encontrar en los escritorios de algunas empresas multinacionales. A saber, el Continente americano estaría en el centro, el europeo a la derecha y el asiático a la izquierda. Una vez más la Unión Soviética detentaría una posición dudosa entre la "asiática" y la "europea", no sólo por su doble condición geográfica, sino porque además no está claro si mantendrá su actual condición de gran potencia "aislada", dependiendo de sus relaciones con Europa y con China, y de su estrategia de enfrentamiento con los EE. UU.

La nueva división internacional del trabajo en una economía mundial que jerarquice los mercados en forma distinta y reencuadre las antiguas potencias de un modo diverso al de la guerra frfa, imprimiría a los intercambios comerciales y a los movimientos de capitales tendencias completamente diferentes de las que se verificaron durante la postguerra. Para comenzar, un mayor grado de apertura externa de la economía norteamericana, de carácter más permanente, permitiría una mayor incorporación de la economía japonesa que tiene una mayor capacidad de acumulación y la tendencia a un superávit estructural en la balanza de pagos. Si los EE. UU. consiguieran acoplar en forma decisiva la economía japonesa a una estrategia convergente de crecimiento a largo plazo, la transnacionalización del capital pasaría a estar centrada en el espacio nacional americano y en su periferia inmediata. Este movimiento centrípeto contrastaría con el dislocamiento de las relaciones económicas internacionales que tuvo lugar hasta mediados del decenio de los setenta, debido a ondas excéntricas, en que Europa, América Latina y Asia (con la excepción del Japón) constituyeron en forma sucesiva los espacios preferenciales de expansión de las filiales norteamericanas. Esta reordenación mundial del comercio y de las inversiones

iver a este respecto la interpretación de Aglietta en "World Gapitalism in Eighties", 1982, N.L.R. 
permitiría que los EE. UU. pasasen a tener un destino distinto de Inglaterra en la primera gran depresión. Como se recordará, Inglaterra fue obligada a financiar una parte de la modernización del mundo capitalista durante el período recesivo de 1980-90 a través de la exportación de capitales, y acabó quedando atrás en su base tecnológica productiva, aun cuando continuase ejerciendo la hegemonía mercantil, financiera y militar hasta 1914.

La base económica norteamericana posee en verdad nítidas ventajas para este movimiento de reconcentración y atracción de capitales. Además de ser continental, la economía norteamericana es más equilibrada en sí misma, pues su industrialización, en todas sus etapas desde el siglo pasado, siempre esturo fuertemente ligada al desenvolvimiento agrícola y de los servicios urbanos. La gran corporación transnacional, como fuente de capitales y modelo de organización industrial, también fue una invención del sistema norteamericano que reveló un gran potencial de acumulación por contener en sí misma todos los rostros del capital: agrario, urbano, mercantil, industrial y financiero. Cuando el mercado interno norteamericano pasó a crecer menos que el potencial de expansión de sus grandes empresas, éstas fueron obligadas a expandirse hacia afuera.

El Japón se encuentra ahora en una situación similar a la de los EE. UU. en la postguerra, sin contar, sin embargo, con una base interna suficiente como para retomar su antiguo dinamismo. El único gran mercado hacia el cual puede exportar crecientemente sus productos, su tecnología y sus capitales, es el norteamericano. Después de haber realizado durante los años setenta su propia transnacionalización en Asia, y en parte del Continente europeo y latinoamericano, le resta ahora una asociación o fusión con el capital norteamericano en el espacio de influencia dominado por éste. Esto no ocurrixá sin conflictos entre las dos partes, dada la asimetría de sus relaciones. La protesta de los capitales norteamericanos perjudicados por la furia exportadora japonesa ya comenzaron, mas la inversión directa tiene su apoyo en la posibilidad de constituir joint-ventures con los capitales locales más dinámicos, y un vasto espacio abierto a la modernización.

$\mathrm{El}$ gran problema para la redefinición del sistema industrial norteamericano es el de su competitividad con el exterior a corto plazo, que incluso podría estimular un nuevo "equilibrio macro-económico", sino el destino a largo plazo de su estructura comercial y productiva $y$, en particular, de los segmentos de dicho sistema constituidos por las filiales de sus corporaciones industriales y bancarias. El sistema bancario norteamericano ya transnacionalizado necesitaba, para salvarse de la crisis y retornar a un puerto seguro, una diplomacia de dólar fuerte, como la que suministró la Reserva Federal. Esta política perjudicaba, sin embargo, y sigue perjudicando 
la posibilidad de recuperar la expansión de la inversión de las filiales industriales en el resto del mundo, así como de recuperar un sólido ritmo de crecimiento de la economía norteamericana a largo plazo.

Por otro lado, los problemas estructurales que plantea la reorganización de la industria norteamericana no pasan sólo por la modernización tecnológica de sus sectores o empresas de punta, como viene sucediendo hasta ahora, sino también por la amortización acelerada del viejo capital industrial ya instalado y por la reestructuración de sus servicios de infraestructura y de utilidad pública. Todo esto es prácticamente imposible de realizar con las actuales tasas de interés y de endeudamiento. Sin una desvalorización lenta de la deuda interna y externa norteamericana, que permita estabilizar los mercados crediticios a largo plazo y reestructurar los mercados de capitales internacionales, no será posible visualizar un horizonte que permita proyectar una recuperación firme de la inversión en estos sectores.

El reflujo del capital bancario norteamericano ya está ocurriendo, el ingreso de capitales extranjeros se concentra rápidamente en los sectores de alta tecnología, y los capitales privados se reorientan aceleradamente hacia los sectores de tecnología intermedia. La "reacción oligopólica" de Knickerbrocker (1973) está operando ahora en sentido inverso, en el sentido de reconcentrar el capital en la propia economía norteamericana. Queda por saber cómo se procesará este nuevo "equilibrio oligopólico" de que hablaban Hymer y Rowthorn (1970) Para eso el destino del Mercado Común Europeo continúa siendo una interrogante sin respuesta en la medida en que la política global europea no adquiera mayor autonomía y coordinación interna.

El ciclo largo de que hablaba Schumpeter en el proceso de crecimiento aún no está a la vista, porque para que se produzca falta rediseñar y financiar sobre nuevas bases el reajcste del sistema energético, el de los transportes y de las comunicaciones, tanto en los EE. UU. como en el resto del mundo. En la mayor parte de los países ello pasa por un reescalonamiento de la deuda externa y pública, imposible de imaginar con el actual sistema crediticio. El actual "ciclo de producto", basado en la informática, no parece, por sí solo, tener un poder suficientemente estimulante para desencadenar una onda de acumulaciones a largo plazo ${ }^{18}$. En definitiva, ningún complejo de innovaciones tecnológicas ha logrado modificar la base de la tecnología mundial sin nuevos mecanismos institucionales y financieros y sin modificar radicalmente la división internacional del trabajo.

\footnotetext{
${ }^{18}$ Además, no parece repetir las características apuntadas por Vernon en su artículo clásico.
} 
Para concluir, el desarrollo futuro de la economía mundial, dada su actual estructura, apunta hacia una arquitectura más compleja que una basada en una simple agregación de "economías nacionales" o de "subsistemas de empresas y bancos transnacionales", como se pensaba hasta hace poco. Mientras no esté más claro si los caminos de transnacionalización del capital atraviesan por una base continental americana y cuál será la capacidad de los EE. UU. para reequilibrar estructuralmente los mapas del Atlántico y del Pacífico, será difícil utilizar con algún rigor la expresión "sistema capitalista internacional".

\section{Como dice Hobsbawn (1979) criticando a Rostow (1978):}

"No hay ninguna razón teórica para presumir que el capitalismo es incapaz de generar otro período de expansión u otra "onda ascendente" de Kondratiev, aunque existen algunas razones empíricas para dudar (desde el punto de vista de Rostow) de de que ésta haya comenzado... Es razonable suponer que la economía capitalista mundial probablemente sobrevivirá a las dificultades globales que actualmente enfrenta, aunque algunos países más débiles tendrán dificultades con ellas".

En este período de transición, que aún está lejos de terminar o de llegar a buen término, es indiscutible la recuperación de la hegemonía norteamericana. Lo que no se conoce es la viabilidad de los EE. UU. para transformarse en forma estable en una economía céntrica a partir de la cual, con o sin un nuevo orden institucional explícito, el mundo sería reorganizado de acuerdo con una nueva geografía económica y política. Lo que tampoco queda claro es el destino de las nuevas periferias de los EE. UU., comenzando por Europa y terminando por América del Sur.

\section{REEERENCIAS BIBLIOGRÁFICAS}

Aglietta, M. "World Capitalism in the Eighties", en New Left Review, No 136, 1982.

ALIBER, R. Z. The International Money Game. Basic Books, N. York, 1979.

FAJNZYLBER, F. El debate industrial en Estados Unidos: entre el desafio japonés y el espectro de Inglaterra. Julio, 1985.
GILPIN, R. R. Us Power and the Multinational Corporations. The Political Economy of Foreign Direct Investment. MacMillan, Londres, 1975.

HobsBawn, E. J. "The development of the world economy".- Cambridge Journal of Economics, 1979.

HyMER, S. y ROWTHORN, R. "Multinational corporations and internatio- 
María da Conceição Tavares / La recuperación de là hegemonfa...

nal oligopoly. The non-american challenge". Es KINDLEBERGER, CP (ed.). The International Corporation, M.I.T. Press, Cambridge, Mass., 1970.

KNICKEBROKER, F. T. “Oligopolistic Reaction and Multinational Enterprises. Harvard University Press, Boston, 1973.

LichtensztejN, S. "América Latina en la Dinámica de la Crisis Financiera Internacional". Ponencia presentada al Seminario "Internacionalización e Industrialización de la Periferia". CIDE, México, 1983.

Moffit, M. The Word's Money. Ed.
Simon and Schuster. N. York, 1983.

Rostow, W. W. The Word Economy: History and Propect. London, MacMillan, 1978.

Tavares, Mc y Teixeira, A. "La internacionalización del Capital y las Transnacionales en la Industria Brasileña". Revista de la cEPAL, agosto de 1981.

Triffin, R. Gold and the Dollar Crisis. Yale University Press, 1960.

VERNON, R. "Investmento Externo e Comercio Internacional no Ciclo do Produto". Orig. en "Quaterley Journal of Economics”. Vol. 80, pp. 190-207, mayo, 1966.

\section{Cuadro 1}

La cuenta corriente de los EE. uU.

\begin{tabular}{|c|c|c|c|c|}
\hline us\$ mil millones & 1981 & 1982 & 1983 & 1984 \\
\hline Exportación de bienes & 237 & 211 & 200 & 217 \\
\hline $\begin{array}{l}\text { Exportación de servicios de } \\
\text { los cuales: }\end{array}$ & 139 & 138 & 192 & 142 \\
\hline Utilidades de inversión & 85 & 84 & 77 & 88 \\
\hline Importación de bienes & -265 & -247 & -261 & -341 \\
\hline $\begin{array}{l}\text { Importación de servicios de } \\
\text { los cuales }\end{array}$ & -97 & -102 & -103 & -123 \\
\hline Pagos de inversiones & -52 & -57 & -54 & -69 \\
\hline Balance comercial & -28 & -36 & -61 & -124 \\
\hline Balance de servicios & 42 & 36 & 29 & 19 \\
\hline Balance de inversiones & 33 & 27 & 24 & 19 \\
\hline \multirow[t]{2}{*}{ Transferencias } & -7 & -9 & -9 & -7 \\
\hline & -6 & -9 & -42 & -112 \\
\hline \multicolumn{5}{|l|}{ Memo itemes (\%) } \\
\hline Cuenta corriente / Utilidades & +1.6 & -2.6 & -12.7 & -32.3 \\
\hline Cuenta corriente/PIB & +0.2 & -0.3 & -1.3 & -3.2 \\
\hline
\end{tabular}

Fuentes us Department of Commerce and estimates.

Publicado en: The Apex Bank Review. Abril 29, 1985. 
Guad ro 2

\section{FLUJOS BRUTOS}

Flujos Brutos de Capital Interno

Largo Plazo

Inversión directa.

Otros

Corto Plazo

Bancos

Entrada bruta de capital externo

or Largo Plazo

- Inversión directa

- Otros

A Corto Plazo

$\smile$ Banco.

Total capital registrado

Capital largo plazo.

Inversión directa extranjera Otros

Capital corto plazo

Exrores y omisiones

Flujos bancarios

Capital Total

\begin{tabular}{rr}
\hline 1980 & 1981 \\
\hline$-78,0$ & $-105,8$ \\
$-28,0$ & $-20,4$ \\
$-19,2$ & $-9,6$ \\
$-8,8$ & $-10,8$ \\
$-3,2$ & $-1,2$ \\
$-46,8$ & $-84,2$ \\
44,2 & 77,0 \\
26,2 & 32,5 \\
16,9 & 32,5 \\
9,3 & 9,4 \\
7,3 & 2,4 \\
10,7 & 42,1 \\
$-39,8$ & $-28,8$ \\
$-1,7$ & 12,0 \\
$-2,3$ & 13,5 \\
0,6 & $-1,5$ \\
4,1 & 1,2 \\
25,0 & 22,3 \\
$-36,1$ & $-42,0$ \\
$-8,7$ & $-6,5$ \\
&
\end{tabular}

8
4
6
8
2
0
5
4
1
8
0
5
2
3
0

1982
$-113,9$
$-9,4$
4,8

4,8
$-14,2$

6,6
$-111,1$

92,6
28,0

23,0
23,0

8,1

3,7

65,9

$-21,3$

13,5

19,7

$-6,1$

10,3

32,9

$-45,1$

11,6

$\begin{array}{rr}1983 & 1984 \\ -48,3 & -17,9 \\ -17,6 & -16,2 \\ -4,9 & -6,0 \\ -12,7 & -10,2 \\ -5,3 & 5,6 \\ -25,4 & -7,3 \\ 75,6 & 88,1 \\ 22,5 & 53,4 \\ 22,5 & 53,4 \\ 11,2 & 32,2 \\ 4,0 & 7,1 \\ 49,1 & 27,6 \\ 27,3 & 70,2 \\ 4,9 & 37,2 \\ 6,4 & 15,2 \\ -1,5 & 22,0 \\ -1,3 & 12,0 \\ 9,3 & 30,0 \\ 23,7 & 20,3 \\ 36,6 & 100,2 \\ & \end{array}$

1981-84.

Memorándum

$$
\text { ftem }
$$

Cambios acumulados

Notas:

a) Transacciones en activos de USA. en el exterior, excluyendo activos de reservas oficiales.

b) Transacciones en activos extranjeros en Ios EE. UU, excluyendo transacciones de autoridades monetarias.

Publicado en: oEGD Economic Outlook N8 37. - Junio 1985. 
Maria da Conceiçäo Tavares / La recuperación de la hegemonfa...

Cuadro 3

DISTRIBUCION DEL NUEVO MERCADO DE LOS ESTADOS UNIDOS

PARTICIPAGION DEL AUMENTO EN IMPORTACIONES

ESTADOS UNIDOS

\begin{tabular}{|c|c|c|c|}
\hline & $\begin{array}{r}1984 \\
\text { on } 1982\end{array}$ & & $\begin{array}{r}1984 \\
\text { on } 1982\end{array}$ \\
\hline Pafses desarrollados & 71,3 & Paises en desarrollo & 26,3 \\
\hline Europa Occidental & 23,3 & $\begin{array}{c}\text { Países en rápida industria } \\
\text { de Asia del Este }\end{array}$ & 17,8 \\
\hline CCEE & 18,3 & Taiwán & 7,5 \\
\hline Alemania & 6,1 & Corea del Sur & 4,7 \\
\hline Italia & 3,3 & Hong-Kong & 1,7 \\
\hline Francia & 3,1 & Singapur & 2,1 \\
\hline Reino Unido & 1,7 & América Latina & 12,1 \\
\hline Holanda & 1,9 & Brasil & 4,2 \\
\hline No CGEE & 5,0 & México & 2,9 \\
\hline Japón & 28,7 & Venezuela & 2,2 \\
\hline \multirow[t]{2}{*}{ Canadá } & 23,3 & Economías planificadas & 2,4 \\
\hline & $\cdots$ & China & 1,0 \\
\hline \multirow[t]{2}{*}{ TOTAL } & 100,0 & & - \\
\hline & & TOTAL & 100,0 \\
\hline
\end{tabular}

FuENTE: vs Department of Commerce.

Guadro 4

IMPORTACIONES DE ESTADOS UNIDOS POR TIPO GENERAL

\begin{tabular}{lccc}
\hline & $\begin{array}{c}\text { Mil } \\
\text { millones }\end{array}$ & $\begin{array}{c}\text { \% Cambio } \\
\text { sobre 1982 }\end{array}$ & del cambio \\
\hline Equipo de maquinaria y transporte & 123,1 & 62,6 & 54,9 \\
Bienes manufacturados & 94,4 & 46,0 & 34,5 \\
Combustibles, minerales, etc. & 63,3 & $-6,4$ & $-5,1$ \\
Alimentos y animales vivos & 19,4 & 23,5 & 4,3 \\
Quimicos, etc. & 14,4 & 45,5 & 5,2 \\
Materiales crudos & 11,9 & 27,7 & 3,0 \\
Otros & 14,7 & 23,2 & $\frac{3,2}{100,0}$ \\
TOTAX & $\underline{31,2}$ & $\underline{33,9}$ & \\
\hline
\end{tabular}

FUENTE: us Department of Commerce.

Publicado en: The Apex Bank Review. Abril 29, 1985. 